\title{
Do Memory CD4 T Cells Keep Their Cell-Type Programming: Plasticity versus Fate Commitment?
}

\section{Epigenome: A Dynamic Vehicle for Transmitting and Recording Cytokine Signaling}

\author{
John L. Johnson ${ }^{1,2}$ and Golnaz Vahedi ${ }^{1,2}$ \\ ${ }^{1}$ Department of Genetics, Perelman School of Medicine, University of Pennsylvania, Philadelphia, \\ Pennsylvania 19104 \\ ${ }^{2}$ Institute for Immunology, Perelman School of Medicine, University of Pennsylvania, Philadelphia, \\ Pennsylvania 19104 \\ Correspondence: vahedi@mail.med.upenn.edu
}

$\mathrm{CD}^{+} \mathrm{T}$ cells are critical for the elimination of an immense array of microbial pathogens. Although there are aspects of helper T-cell differentiation that can be modeled as a classic cell-fate commitment, $\mathrm{CD} 4^{+} \mathrm{T}$ cells also maintain considerable flexibility in their transcriptional program. Here, we present an overview of chromatin biology during cellular reprogramming and, within this context, envision how the scope of cellular reprogramming may be expanded to further our understanding of the controversy surrounding CD4 ${ }^{+} \mathrm{T}$ lymphocyte plasticity or determinism.

\section{GREAT DEBATES}

What are the most interesting topics likely to come up over dinner or drinks with your colleagues? Or, more importantly, what are the topics that don't come up because they are a little too controversial? In Immune Memory and Vaccines: Great Debates, Editors Rafi Ahmed and Shane Crotty have put together a collection of articles on such questions, written by thought leaders in these fields, with the freedom to talk about the issues as they see fit. This short, innovative format aims to bring a fresh perspective by encouraging authors to be opinionated, focus on what is most interesting and current, and avoid restating introductory material covered in many other reviews.

The Editors posed 13 interesting questions critical for our understanding of vaccines and immune memory to a broad group of experts in the field. In each case, several different perspectives are provided. Note that while each author knew that there were additional scientists addressing the same question, they did not know who these authors were, which ensured the independence of the opinions and perspectives expressed in each article. Our hope is that readers enjoy these articles and that they trigger many more conversations on these important topics.

Editors: Shane Crotty and Rafi Ahmed

Additional Perspectives on Immune Memory and Vaccines: Great Debates available at www.cshperspectives.org

Copyright (C) 2018 Cold Spring Harbor Laboratory Press; all rights reserved; doi: 10.1101/cshperspect.a028779 Cite this article as Cold Spring Harb Perspect Biol 2018;10:a028779 
$\mathrm{T}_{\mathrm{p}}^{\mathrm{h}}$ he genetic information encoded in DNA is presented in the context of chromatin, a complex of nucleic acid and associated proteins called histones. The dynamic nature of the chromatin is a defining feature of the epigenetic regulation. The regulation of $\mathrm{CD} 4^{+} \mathrm{T}$ cells similar to any other cell type is therefore tightly linked with the epigenome-the combinatorial variance in localization and modifications of chromatin factors and underlying DNA. Propelled by rapid technological advances in sequencing, the field of epigenomics is enjoying unprecedented growth with no sign of deceleration ( $\mathrm{Ri}$ vera and Ren 2013). An expanding number of immunologists are working to explore exciting frontiers in epigenomic regulation of immune cells. Consequently, the number of data sets and publications has grown in recent years. The theme emerging from these genome-scale studies is that the chromatin structure is an attractive template for both transmitting and recording immunological events. For example, the demethylation of the $\mathrm{PD}-1$ promoter is recorded during the effector phase of T-cell exhaustion (Youngblood et al. 2011), whereas cytokine signaling in $\mathrm{CD}^{+}{ }^{+} \mathrm{T}$ helper cells can be transmitted through gain and loss of histone acetylation at thousands of genomic regions (Vahedi et al. 2012, 2015). Here, we aim to discuss the controversy surrounding $\mathrm{CD}^{+}{ }^{+} \mathrm{T}$ lymphocyte plasticity or determinism mostly from a chromatin biology perspective. This article has a three-prong focus: We start by discussing how cell fate is regulated during development. We then focus on reprogramming studies and the characteristics of factors capable of inducing cell-fate changes. And finally we evaluate $\mathrm{CD} 4^{+}$T-cell plasticity from the chromatin biology perspective.

\section{HOW IS CELL FATE DETERMINED?}

Cellular-state information between generations of developing cells is propagated through the epigenome particularly via the accessible parts of the chromatin. Consistent patterns of gain and loss of chromatin accessibility has been reported as cells progress from embryonic stem cells to terminal fates (Stergachis et al. 2013). Chromatin accessibility together with covalent modifications of histones is controlled in large part by the action of multiple transcription factors that recognize and bind specific sequences in the genome. Rather than one regulatory protein being singularly responsible for creating the chromatin state and determining each cell type, particular combinations of transcription factors elicit cell-fate changes and maintain cell identity (Iwafuchi-Doi and Zaret 2016). The emerging theme from recent studies is that the chromatin state has a hierarchical organization where every layer is regulated by distinct groups of transcription factors. The first layer relates to a small number of transcription factors who act first on the chromatin and are referred to as "pioneer transcription factors." These factors are distinguished from other transcription factors by their ability to bind their cognate DNA sites directly on the nucleosome, even in chromatin that is locally compacted by linker histone (Zaret and Mango 2016).

Such pioneer transcription factors initiate cooperative interactions with other transcription factors to elicit changes in local chromatin structure. A second layer in this hierarchical organization consists of transcription factors such as AP-1 family members JUNB, BATF, and IRF4, which further prime parts that later become associated with more specific and dynamic factors (Garber et al. 2012; Kurachi et al. 2014). The bottom layer, particularly essential for $\mathrm{CD}_{4}^{+} \mathrm{T}$-cell biology, relates to transcription factors downstream of signal transduction pathways. These signal-dependent transcription factors are dynamic and control more specific sets of genes that have common biological functions. For instance, the signal transducers and activators of transcription (STAT) proteins target the late induced T-helper-specific chromatin states, while the nuclear factor $\kappa \mathrm{B}(\mathrm{NF}-\kappa \mathrm{B})$ factors Rel, Relb, and NFKB1 target the inflammatory program (Garber et al. 2012; Vahedi et al. 2012; Ostuni et al. 2013).

\section{HOW FIXED IS THE DIFFERENTIATED STATE?}

The prevailing paradigm in cell development has been that somatic cells become irreversibly committed to their fate and lose potency as they specialize. Despite physiological settings, exper- 
iments performed several decades ago showed that the fusion of different pairs of cell types can awaken dormant gene-expression programs (Blau 1989). Subsequently, breakthroughs in cellular reprogramming techniques, recognized by a Nobel Prize, convinced us that plasticity can be induced and "fate" can be changed. Reprogramming studies on the use of transcription factors to interconvert cells of different types brought to light the distinguished role of pioneer factors. Direct assessments of the initial binding of the induced pluripotency factors Oct4, Sox2, Klf4, and c-Myc showed that Oct4 and Sox2, and to a lesser extent Klf4 target predominantly silent and inaccessible chromatinresistant to DNaseI-when they are forcibly expressed in human fibroblast cells (Soufi et al. 2012). Studies in immune cells also showed that when $\mathrm{C} / \mathrm{EBPa}$ is ectopically expressed in pre- $\mathrm{B}$ cells, it can convert $\mathrm{B}$ cells to macrophages by targeting closed chromatin (van Oevelen et al. 2015). Together, cell fate can be altered experimentally as a result of forced expression of various combinations of transcription factors typically including pioneer factors.

\section{CELL FATE IN CD4 ${ }^{+}$T CELLS}

We have reviewed concepts in development and reprogramming to highlight that $\mathrm{CD} 4^{+} \mathrm{T}$ cells, like all other cells, are packaged into chromatin. Specialized CD $4^{+}$T cells (e.g., T helper 1 cells), maintain their fate until environmental changes lead to the expression of "influential" transcription factors that can potentiate cells to change their program. Given the stability of the differentiated state in vivo, an understanding of the regulation of $\mathrm{CD}^{+}$T-cell differentiation by mechanisms that allow the type of plasticity observed in reprogramming is critical for our understanding of vaccines and immune memory.

Early in vitro studies argued that once a $\mathrm{CD} 4^{+} \mathrm{T}$ cell had chosen its fate, it would not easily switch to another fate, even if exposed to the cytokines that drove differentiation to the opposing subset (Mosmann and Coffman 1989; O'Shea and Paul 2010; Yamane and Paul 2012). This dogma has been challenged over the last decade because the possibility of polarized T cells to repolarize toward mixed or alternative fates have been reported (DuPage and Bluestone 2016). For example, recent lineage-tracing systems in mice showed that endogenously polarized $\mathrm{CD} 4^{+} \mathrm{T}$ cells from many subsets can alter their phenotype during their life span (Zhou et al. 2009b; Hirota et al. 2011; Wilhelm et al. 2011; Ahlfors et al. 2014). Furthermore, the phenotypic plasticity of regulatory $\mathrm{T}$ cells that mirrors each $\mathrm{T}$ helper cell subset supports a hypothesis of an inherent flexibility of T cells, both inflammatory and regulatory, to adapt their function to changing environments (DuPage and Bluestone 2016). These in vitro and in vivo studies, extensively reviewed elsewhere (Wilson et al. 2009; Zhou et al. 2009a; Murphy and Stockinger 2010; O'Shea and Paul 2010; DuPage and Bluestone 2016), suggest that $\mathrm{CD}^{+} \mathrm{T}$ cells are adaptable and can show phenotypic plasticity in response to changing contexts.

\section{REGULATION OF PLASTICITY IN CD $4^{+}$ T CELLS}

In this perspective, we propose that plasticity of $\mathrm{CD}^{+}{ }^{+} \mathrm{T}$ cells works by the same mechanism that initially selected the first fate. If a cell population is able to respond to new signals because it expresses that specific extracellular receptor, has the cytoplasmic means of signaling, and the ability to induce the transcription factors that have strong impact on the chromatin, then the cellular identity at the epigenetic level can be modified to allow the cell to take on new identity and function.

The $\mathrm{CD}^{+}{ }^{+} \mathrm{T}$ cell's initial activation through T-cell receptor (TCR) results in the activation of primed elements rather than selection of new regions (Allison et al. 2016). The presence of polarizing cytokines initiates the process of selecting the T-cell fate with genome-scale epigenetic changes (Ciofani et al. 2012; Vahedi et al. 2012). In the face of a new challenge or extracellular environment, the presence of new cytokine signals is propagated through available cytokine receptors and cytoplasmic signaling events into the nucleus. These events induce expression of transcription factors with varying degrees of intrinsic ability to modify the chromatin environment 
(Vahedi et al. 2012). Although branding transcription factors to "master" regulators attracted a lot of attention among T-cell biologists (Rothenberg 2014), we propose to set aside the semantics and what the words "pioneer" or "master" may imply. Identifying T-helper-specific transcription factors with an intrinsic ability to bind silent chromatin and consequently alter T-cell fate has an important implication for understanding T-cell plasticity.

\section{INTEGRATING GENOMIC DATASETS FOR A BETTER UNDERSTANDING OF SUBSETS}

Deciphering mechanisms of $\mathrm{CD} 4^{+}$T-cell plasticity requires a more precise definition of these same subsets (Fig. 1). We argue that this is because populations of cells may appear to fit into a certain subset based on traditional measures (i.e., flow cytometry), but is actually composed of cells with different histories of cytokine exposure that has been imprinted onto the chromatin. These differences may not be immediately apparent, but may have major influence on cellular function in the right context. Highly parametric multidimensional measurements of $\mathrm{T}$ cells by mass or flow cytometry has revealed an overwhelming number of subpopulations in any given subset during an immune response (Newell et al. 2012; Gaudilliere et al. 2014; O'Gorman et al. 2015). The challenge remains in determining whether these states are transi-

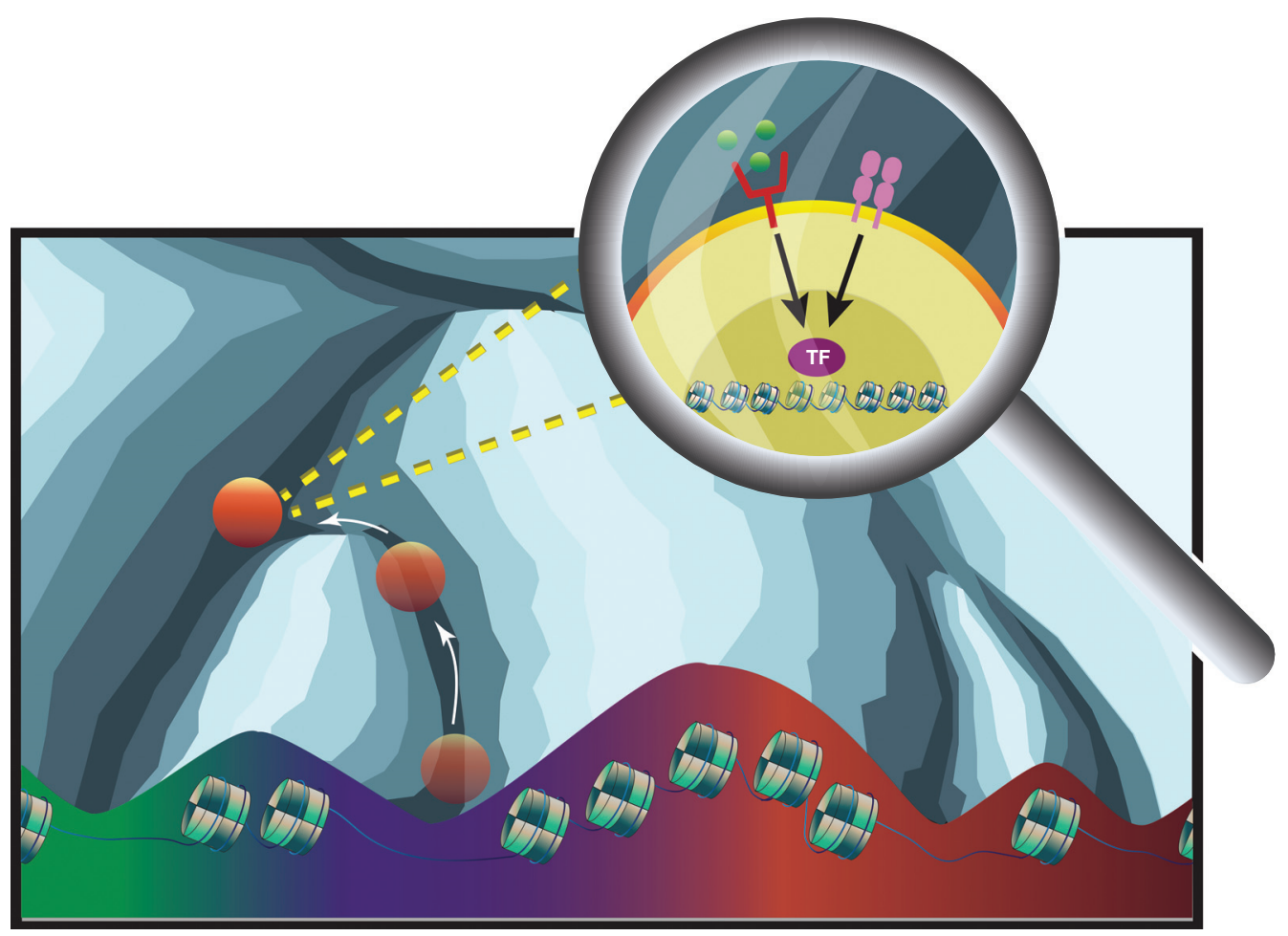

Figure 1. $\mathrm{CD}^{+}{ }^{+}$-cell plasticity regulated by transcription factors (TF) that control the accessible chromatin. The process of differentiation lowers the potential of the cell to differentiate to other lineages as visualized by Waddington's landscape. The cell eventually becomes committed to a lineage and resides in the valleys of accessible chromatin. New signaling events, through T-cell receptor (TCR) signaling and extracellular receptors, are propagated to the nucleus through the appropriate cytoplasmic machinery. This causes the expression of transcription factors that modulate chromatin accessibility to allow for the cell to obtain new cell identity and function. Epigenetic regulatory mechanisms such as DNA methylation and histone modifications can either enhance or inhibit this process. 
Do Memory CD4 T Cells Keep Their Cell-Type Programming?

tory or stable and to determine their functional status or disease relevance.

Integrating epigenetic measurements is an attractive solution for more precise definitions of cell identity. The relative stability of cell identity conferred by epigenetic mechanisms at the genome-wide level makes this possible. Chromatin accessibility measurements by DNase I hypersensitivity or the new and robust assay ATAC-seq has provided an excellent foundation of cell identity. A remarkable example is a recent comparison of chromatin accessibility landscapes in innate and adaptive $\mathrm{T}$ cells revealing similarity and differences in these two distinct cell types (Shih et al. 2016).

\section{SINGLE-CELL HETEROGENEITY}

Although not a novel observation, cellular heterogeneity in once seemingly homogenous populations is even more apparent with the advent of new technologies to take single-cell measurements. Variability in canonical subsets may help fill gaps in proposed links between certain CD4 subsets and disease. Heterogeneity may not be ultimately meaningful in most tissue systems in multicellular organisms, as a certain level of homeostasis is required. However, the immune system is one environment in which cellular heterogeneity is of higher priority. Rare cells with the ability to respond to everchanging pathogens provide the edge necessary to overcome these pathogens. Indeed, heterogeneity of the lymphocyte compartment encoded in the diverse antigen receptor repertoire has granted us a mechanism that ensures a small proportion of the lymphocyte population will have the means of recognition for nearly any new pathogen. Much attention is being focused on deconstructing the signaling and epigenetic mechanisms that give rise to variability and to assess the impact of that variability in the host immune response. As a result of recent genomics tools such as single-cell RNA-seq (Kolodziejczyk et al. 2015) and ATAC-seq (Buenrostro et al. 2015) together with revolutionary singlecell proteomics, we are poised to improve our understanding of cell identity from a single-cell perspective.

\section{LINEAGE TRACING IS IMPORTANT IN DETERMINING PAST, PRESENT, AND FUTURE}

We posit that snapshot measurements of the CD4 compartment in response to an immune stimulus does not allow us to adequately resolve multiple underlying populations at the epigenetic level. As discussed above, the influence of previous cytokine exposure can be recorded in the chromatin. Understanding how this history may influence future behavior and how a seemingly homogenous population of cells might diverge in response to new stimuli is critically important. If the goal is to understand the transcriptional circuitry that leads to polarized subsets of CD4 $\mathrm{T}$ cells, it stands to reason that understanding how these epigenetics states corresponds to function is of equal importance. Addressing these questions will not only require an integration of genomics and phenotypic data, but also better methods of lineage tracing. The advent of CRISPR-Cas9 brings the ability to genetically track cells in an ongoing manner and to serve as signposts from which we can take our snapshot measurements of the cell to understand its trajectory (McKenna et al. 2016).

\section{CONCLUDING REMARKS}

Initiated by the application of microarrays, the last decade unraveled the battery of transcription factors essential in T-helper-cell differentiation. Yet, we have limited knowledge about the efficacy of these proteins on the chromatin and their relative ability to alter the accessibility landscapes and ultimately T-cell fate in the periphery. Novel techniques in genomics, epigenomics, proteomics, single-cell biology, and gene editing together with computational techniques developed for data integration can help us fill these gaps. Understanding the mechanisms underlying plasticity in $\mathrm{CD}^{+}{ }^{+} \mathrm{T}$ cells will provide us with the opportunity to tailor the $\mathrm{CD} 4^{+}$responses for better vaccination and to reinvigorate $\mathrm{T}$-cell responses in chronic infection and cancer. Overcoming the stable and defined chromatin state through the expression of transcription factors with effectuating prop- 
erties can potentially overcome mechanisms of inhibition and allows new signals_-and fatesto be propagated to the nucleus to ultimately control the outcome of the immune response.

\section{ACKNOWLEDGMENTS}

This work is supported by the National Institute of Allergy and Infectious Diseases (NIAID) (K22AI112570 to G.V). We thank Carol A. Clifton for Figure 1.

\section{REFERENCES}

Ahlfors H, Morrison PJ, Duarte JH, Li Y, Biro J, Tolaini M, Di Meglio P, Potocnik AJ, Stockinger B. 2014. IL-22 fate reporter reveals origin and control of IL-22 production in homeostasis and infection. J Immunol 193: 4602-4613.

Allison KA, Sajti E, Collier JG, Gosselin D, Troutman TD, Stone EL, Hedrick SM, Glass CK. 2016. Affinity and dose of TCR engagement yield proportional enhancer and gene activity in $\mathrm{CD}^{+} \mathrm{T}$ cells. eLife 5: e10134.

Blau HM. 1989. How fixed is the differentiated state? Lessons from heterokaryons. Trends Genet 5: 268-272.

Buenrostro JD, Wu B, Litzenburger UM, Ruff D, Gonzales ML, Snyder MP, Chang HY, Greenleaf WJ. 2015. Singlecell chromatin accessibility reveals principles of regulatory variation. Nature 523: 486-490.

Ciofani M, Madar A, Galan C, Sellars M, Mace K, Pauli F, Agarwal A, Huang W, Parkurst CN, Muratet M, et al. 2012. A validated regulatory network for th17 cell specification. Cell 151: 289-303.

DuPage M, Bluestone JA. 2016. Harnessing the plasticity of $\mathrm{CD} 4{ }^{+} \mathrm{T}$ cells to treat immune-mediated disease. Nat Rev Immunol 16: 149-163.

Garber M, Yosef N, Goren A, Raychowdhury R, Thielke A, Guttman M, Robinson J, Minie B, Chevrier N, Itzhaki Z, et al. 2012. A high-throughput chromatin immunoprecipitation approach reveals principles of dynamic gene regulation in mammals. Mol Cell 47: 810-822.

Gaudilliere B, Fragiadakis GK, Bruggner RV, Nicolau M, Finck R, Tingle M, Silva J, Ganio EA, Yeh CG, Maloney WJ, et al. 2014. Clinical recovery from surgery correlates with single-cell immune signatures. Sci Transl Med 6: 255ra131.

Hirota K, Duarte JH, Veldhoen M, Hornsby E, Li Y, Cua DJ, Ahlfors H, Wilhelm C, Tolaini M, Menzel U, et al. 2011. Fate mapping of IL-17-producing T cells in inflammatory responses. Nat Immunol 12: 255-263.

Iwafuchi-Doi M, Zaret KS. 2016. Cell fate control by pioneer transcription factors. Development 143: 1833-1837.

Kolodziejczyk AA, Kim JK, Svensson V, Marioni JC, Teichmann SA. 2015. The technology and biology of single-cell RNA sequencing. Mol Cell 58: 610-620.

Kurachi M, Barnitz RA, Yosef N, Odorizzi PM, Dilorio MA, Lemieux ME, Yates K, Godec J, Klatt MG, Regev A, et al. 2014. The transcription factor BATF operates as an essen- tial differentiation checkpoint in early effector $\mathrm{CD}^{+} \mathrm{T}$ cells. Nat Immunol 15: 373-383.

McKenna A, Findlay GM, Gagnon JA, Horwitz MS, Schier AF, Shendure J. 2016. Whole-organism lineage tracing by combinatorial and cumulative genome editing. Science 353: aaf7907.

Mosmann TR, Coffman RL. 1989. TH1 and TH2 cells: Different patterns of lymphokine secretion lead to different functional properties. Annu Rev Immunol 7: 145-173.

Murphy KM, Stockinger B. 2010. Effector T cell plasticity: Flexibility in the face of changing circumstances. Nat Immunol 11: 674-680.

Newell EW, Sigal N, Bendall SC, Nolan GP, Davis MM. 2012. Cytometry by time-of-flight shows combinatorial cytokine expression and virus-specific cell niches within a continuum of $\mathrm{CD}^{+} \mathrm{T}$ cell phenotypes. Immunity 36: $142-152$.

O'Gorman WE, Hsieh EW, Savig ES, Gherardini PF, Hernandez JD, Hansmann L, Balboni IM, Utz PJ, Bendall SC Fantl WJ, et al. 2015. Single-cell systems-level analysis of human Toll-like receptor activation defines a chemokine signature in patients with systemic lupus erythematosus. J Allergy Clin Immunol 136: 1326-1336.

O'Shea JJ, Paul WE. 2010. Mechanisms underlying lineage commitment and plasticity of helper $\mathrm{CD} 4^{+} \mathrm{T}$ cells. Science 327: 1098-1102.

Ostuni R, Piccolo V, Barozzi I, Polletti S, Termanini A, Bonifacio S, Curina A, Prosperini E, Ghisletti S, Natoli G. 2013. Latent enhancers activated by stimulation in differentiated cells. Cell 152: 157-171.

Rivera CM, Ren B. 2013. Mapping human epigenomes. Cell 155: 39-55.

Rothenberg EV. 2014. The chromatin landscape and transcription factors in T cell programming. Trends Immunol 35: 195-204.

Shih HY, Sciume G, Mikami Y, Guo L, Sun HW, Brooks SR, Urban JFJr., Davis FP, Kanno Y, O’Shea JJ. 2016. Developmental acquisition of regulomes underlies innate lymphoid cell functionality. Cell 165: 1120-1133.

Soufi A, Donahue G, Zaret KS. 2012. Facilitators and impediments of the pluripotency reprogramming factors' initial engagement with the genome. Cell 151: 994-1004.

Stergachis AB, Neph S, Reynolds A, Humbert R, Miller B, Paige SL, Vernot B, Cheng JB, Thurman RE, Sandstrom $\mathrm{R}$, et al. 2013. Developmental fate and cellular maturity encoded in human regulatory DNA landscapes. Cell 154: 888-903.

Vahedi G, Takahashi H, Nakayamada S, Sun HW, Sartorelli V, Kanno Y, O'Shea JJ. 2012. STATs shape the active enhancer landscape of T cell populations. Cell 151: 981993.

Vahedi G, Kanno Y, Furumoto Y, Jiang K, Parker SC, Erdos MR, Davis SR, Roychoudhuri R, Restifo NP, Gadina M, et al. 2015. Super-enhancers delineate disease-associated regulatory nodes in T cells. Nature 520: 558-562.

van Oevelen C, Collombet S, Vicent G, Hoogenkamp M, Lepoivre C, Badeaux A, Bussmann L, Sardina JL, Thieffry $\mathrm{D}$, Beato $\mathrm{M}$, et al. 2015. C/EBP $\alpha$ activates pre-existing and de novo macrophage enhancers during induced preB cell transdifferentiation and myelopoiesis. Stem Cell Rep 5: 232-247. 
Do Memory CD4 T Cells Keep Their Cell-Type Programming?

Wilhelm C, Hirota K, Stieglitz B, Van Snick J, Tolaini M, Lahl K, Sparwasser T, Helmby H, Stockinger B. 2011. An IL-9 fate reporter demonstrates the induction of an innate IL9 response in lung inflammation. Nat Immunol 12: 1071-1077.

Wilson CB, Rowell E, Sekimata M. 2009. Epigenetic control of T-helper-cell differentiation. Nat Rev Immunol 9: 91-105.

Yamane H, Paul WE. 2012. Memory $\mathrm{CD}^{+}$T cells: Fate determination, positive feedback and plasticity. Cell Mol Life Sci 69: 1577-1583.

Youngblood B, Oestreich KJ, Ha SJ, Duraiswamy J, Akondy RS, West EE, Wei Z, Lu P, Austin JW, Riley JL, et al. 2011. Chronic virus infection enforces demethylation of the locus that encodes PD- 1 in antigen-specific $\mathrm{CD} 8^{+} \mathrm{T}$ cells. Immunity 35: 400-412.

Zaret KS, Mango SE. 2016. Pioneer transcription factors, chromatin dynamics, and cell fate control. Curr Opin Genet Dev 37: 76-81.

Zhou L, Chong MMW, Littman DR. 2009a. Plasticity of $\mathrm{CD}^{+}{ }^{+} \mathrm{T}$ cell lineage differentiation. Immunity 30: 646655.

Zhou X, Bailey-Bucktrout SL, Jeker LT, Penaranda C, Martínez-Llordella M, Ashby M, Nakayama M, Rosenthal W, Bluestone JA. 2009b. Instability of the transcription factor Foxp3 leads to the generation of pathogenic memory T cells in vivo. Nat Immunol 10: 1000-1007. 


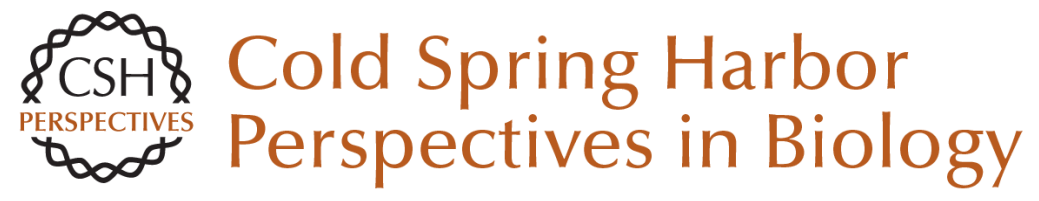

\section{Do Memory CD4 T Cells Keep Their Cell-Type Programming: Plasticity versus Fate Commitment?: Epigenome: A Dynamic Vehicle for Transmitting and Recording Cytokine Signaling}

John L. Johnson and Golnaz Vahedi

Cold Spring Harb Perspect Biol 2018; doi: 10.1101/cshperspect.a028779 originally published online April 21, 2017

\section{Subject Collection Immune Memory and Vaccines: Great Debates}

Is There Natural Killer Cell Memory and Can It Be Harnessed by Vaccination?: Can Natural Killer and CD8 T Cells Switch Jobs?

Christine A. Biron and Marcus Altfeld

Is There Natural Killer Cell Memory and Can It Be Harnessed by Vaccination?: Vaccination Strategies Based on NK Cell and ILC Memory Megan A. Cooper, Todd A. Fehniger and Marco Colonna

Is It Possible to Develop Cancer Vaccines to Neoantigens, What Are the Major Challenges, and How Can These Be Overcome?: Neoantigens as Vaccine Targets for Cancer Haydn T. Kissick

Is It Possible to Develop Cancer Vaccines to Neoantigens, What Are the Major Challenges, and How Can These Be Overcome?: Neoantigens: Nothing New in Spite of the Name

Olivera J. Finn and Hans-Georg Rammensee
Is There Natural Killer Cell Memory and Can It Be Harnessed by Vaccination?: NK Cell Memory and Immunization Strategies against Infectious Diseases and Cancer Joseph C. Sun and Lewis L. Lanier

Is There Natural Killer Cell Memory and Can It Be Harnessed by Vaccination?: Natural Killer Cells in Vaccination

Harold R. Neely, Irina B. Mazo, Carmen Gerlach, et al.

Is It Possible to Develop Cancer Vaccines to Neoantigens, What Are the Major Challenges, and How Can These Be Overcome?: Targeting the Right Antigens in the Right Patients Stephen P. Schoenberger

Which Dengue Vaccine Approach Is the Most Promising, and Should We Be Concerned about Enhanced Disease after Vaccination?: There Is Only One True Winner Scott B. Halstead

For additional articles in this collection, see http://cshperspectives.cshlp.org/cgi/collection/

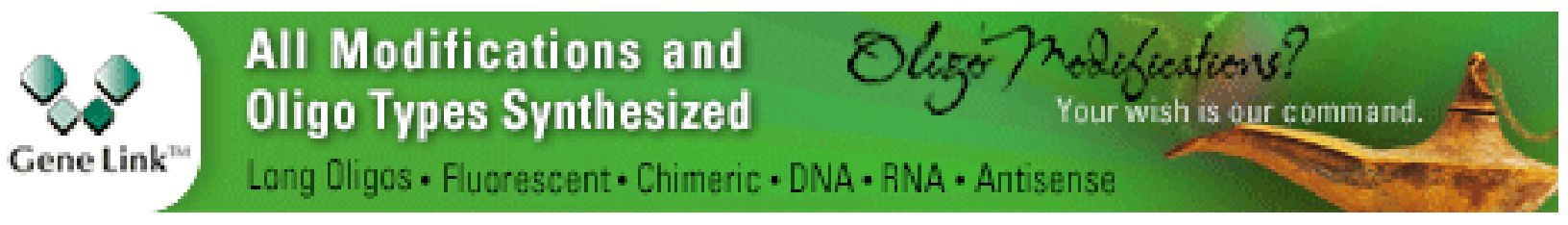


Which Dengue Vaccine Approach Is the Most Promising, and Should We Be Concerned about Enhanced Disease after Vaccination?: The Challenges of a Dengue Vaccine

Gavin Screaton and Juthathip Mongkolsapaya

Which Dengue Vaccine Approach Is the Most Promising, and Should We Be Concerned about Enhanced Disease after Vaccination?: The Path to a Dengue Vaccine: Learning from Human Natural Dengue Infection Studies and Vaccine Trials Aravinda M. de Silva and Eva Harris

Is It Possible to Develop a "Universal" Influenza Virus Vaccine?: Potential for a Universal Influenza Vaccine James E. Crowe, Jr.

Is It Possible to Develop a "Universal" Influenza Virus Vaccine?: Outflanking Antibody Immunodominance on the Road to Universal Influenza Vaccination

Davide Angeletti and Jonathan W. Yewdell
Which Dengue Vaccine Approach Is the Most Promising, and Should We Be Concerned about Enhanced Disease after Vaccination?: Questions Raised by the Development and Implementation of Dengue Vaccines: Example of the Sanofi Pasteur Tetravalent Dengue Vaccine Bruno Guy

Which Dengue Vaccine Approach Is the Most Promising, and Should We Be Concerned about Enhanced Disease after Vaccination?: The Risks of Incomplete Immunity to Dengue Virus Revealed by Vaccination

Stephen S. Whitehead and Kanta Subbarao

Is It Possible to Develop a "Universal" Influenza Virus Vaccine?: Immunogenetic Considerations Underlying B-Cell Biology in the Development of a Pan-Subtype Influenza A Vaccine Targeting the Hemagglutinin Stem Sarah F. Andrews, Barney S. Graham, John R. Mascola, et al.

Is It Possible to Develop a "Universal" Influenza Virus Vaccine?: Potential Target Antigens and Critical Aspects for a Universal Influenza Vaccine Florian Krammer, Adolfo García-Sastre and Peter Palese

For additional articles in this collection, see http://cshperspectives.cshlp.org/cgi/collection/

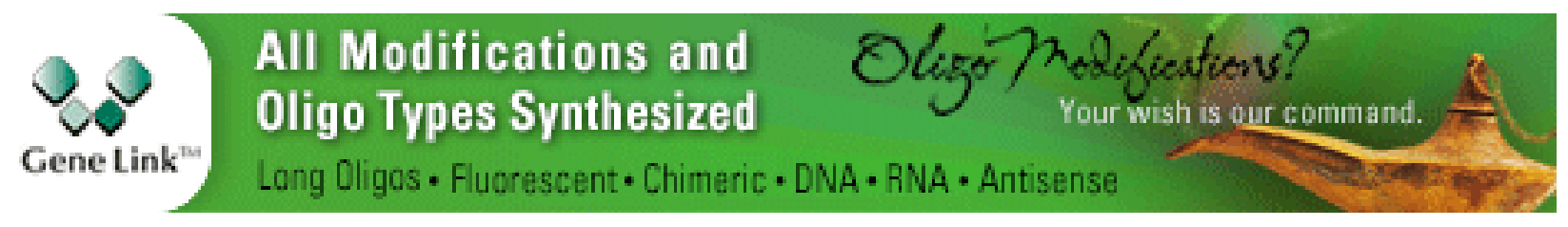

